\title{
ESDD
}

$4,25-47,2013$

\section{Estimation of the climate feedback parameter by using radiative fluxes from CERES EBAF}

\section{P. Björnbom}

KTH Royal Institute of Technology, c/o Pehr Björnbom, Kometvägen 1, 18333 Täby, Sweden Received: 16 December 2012 - Accepted: 20 December 2012 - Published: 9 January 2013 Correspondence to: P. Björnbom (pehrbjor@kth.se)

Published by Copernicus Publications on behalf of the European Geosciences Union.

\section{Using radiative EBAF \\ P. Björnbom} fluxes from CERES

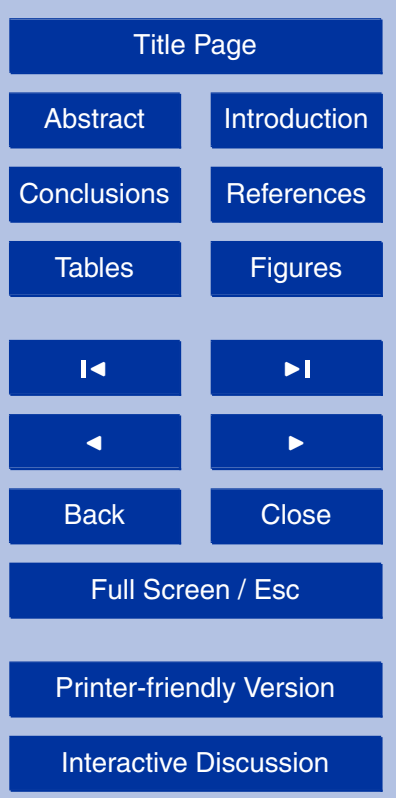




\section{Abstract}

Top-of-the-Atmosphere (TOA) net radiative flux anomalies from Clouds and Earth's Radiant Energy Systems (CERES) Energy Balanced and Filled (EBAF) and surface air temperature anomalies from HadCRUT3 were compared for the time interval Septem-

5 ber 2000-May 2011. In a phase plane plot with the radiative flux anomalies lagging the temperature anomalies with 7 months the phase plane curve approached straight lines during about an eight months long period at the beginning and a five year period at the end of the interval. Both of those periods, but more clearly the latter one, could be connected to the occurrence of distinct EI Niño Southern Oscillation (ENSO) episodes.

10 This result is explained by using a hypothesis stating that non-radiative forcing connected to the ENSO is dominating the temperature changes during those two periods and that there is a lag between the temperature change and the radiative flux feedback. According to the hypothesis the slopes of the straight lines equal the value of the climate feedback parameter. By linear regression based on the mentioned five year pe15 riod the value of the climate feedback parameter was estimated to $5.5 \pm 0.6 \mathrm{~W} \mathrm{~m}^{-2} \mathrm{~K}^{-1}$ ( \pm two standard errors).

\section{Introduction}

The estimation of the value of the climate feedback parameter from satellite data of the radiative flux from Earth to space has caused some recent debate in the scientific 20 literature.

Trenberth et al. (2011) have discussed this issue in a critical review. Trenberth et al. (2010) also address some of the background of this problem. For a recent more general overview of the literature on global climate feedbacks see the Introduction by Masters (2012).

25 It has been suggested that the climate feedback parameter (both the total and its parts for example connected to clouds) may be determined by a linear regression of
ESDD

$4,25-47,2013$

\section{Using radiative fluxes from CERES EBAF}

P. Björnbom

\section{Title Page}

Abstract Introduction

Conclusions

Tables References Figures

14

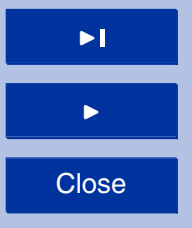

Back

Close

Full Screen / Esc

Printer-friendly Version

Interactive Discussion

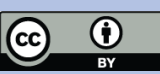


the change in the net radiative flux anomaly versus the change in the surface air or the sea surface temperature anomaly (Trenberth et al., 2010; Dessler, 2010). However, Spencer and Braswell (2010) suggested that such a method would be ambiguous considering its failure to separate the changes in the net radiative flux anomaly due 5 to feedback (caused by temperature changes) from changes due to varying radiative forcing through, for example, changing clouds. Masters (2012) found that the method used by Dessler (2010) generated large uncertainties causing difficulties in drawing conclusions from the results.

The climate feedback parameter is closely related to the equilibrium climate sensitiv10 ity (Gregory et al., 2004). For example, a true value of this parameter of $1.2 \mathrm{Wm}^{-2} \mathrm{~K}^{-1}$, which is a typical value from climate model simulations (Gregory et al., 2004), corresponds to a climate sensitivity of $3.7 / 1.2=3.1 \mathrm{~K}$ for a doubling of the carbon dioxide mixing ratio.

An unusually high value of the climate feedback parameter of $6 \mathrm{Wm}^{-2} \mathrm{~K}^{-1}$ is sug15 gested by the phase plane plots in Spencer and Braswell (2010). This corresponds to a very low climate sensitivity that disagrees with the majority of the other estimations of the climate sensitivity (Knutti and Hegerl, 2008; Randall et al., 2007; Huber et al., 2011). A discussion of the various methods for estimation of the climate sensitivity is beyond the scope of this work. Here we discuss a method for estimating the value of the climate feedback parameter from satellite radiative flux data and leave the question how to relate the result from this method to the equilibrium climate sensitivity to future work.

In Trenberth et al. $(2010,2011)$ and Dessler (2011) the authors draw special attention to the role of EI Niño Southern Oscillation (ENSO) during the first decade of this millennium. Loeb et al. (2012) have discussed how TOA radiative flux anomalies have changed due to ENSO events.

In this work it is suggested from the analysis of the relation between the surface air temperature anomaly and the TOA net radiative flux anomaly, derived from the Clouds and Earth's Radiant Energy Systems (CERES) Energy Balanced and Filled (EBAF)
ESDD

4, 25-47, 2013

\section{Using radiative fluxes from CERES EBAF}

P. Björnbom

\section{Title Page}

Abstract Introduction

Conclusions

Tables References Figures

14

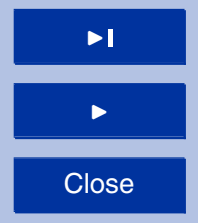

Back

Close

Printer-friendly Version

Interactive Discussion 
product (Loeb et al., 2009), that an assumption that ENSO has completely dominated the temperature changes during the whole period September 2000-May 2011 is not valid. However, it is suggested as a hypothesis that ENSO dominated the change in the surface air temperature anomaly in parts of this period especially the five year period 5 mid-2006 to mid-2011. The study of that period appears to be useful for estimating a value of the climate feedback parameter by using phase plane plots similar to those suggested by Spencer and Braswell (2010).

\section{Theoretical background}

According to the concepts of radiative forcing and feedback, as described by Gregory 10 et al. (2004), the net downward radiative flux at the top of the atmosphere (TOA) is separated into a forcing term, positive downwards, and a feedback term, positive upwards.

$N=F-H$

Gregory et al. (2004) adopted results from model experiments with Global Circulation 15 Models (GCMs) that the feedback term is proportional to the surface air temperature change:

$H=\alpha \Delta T$

This gives the following simple linear model equation for the TOA radiative flux:

$N=F-\alpha \Delta T$

20 Gregory et al. (2004) used this simple model to study feedback in Global Circulation Models (GCMs) and coupled Atmospheric Ocean GCMs (AOGCMs) in model experiments with $2 \times \mathrm{CO}_{2}$ och $4 \times \mathrm{CO}_{2}$. In such experiments the radiative forcing in principle is changed instantaneously and after that kept constant.
ESDD

$4,25-47,2013$

\section{Using radiative fluxes from CERES EBAF}

P. Björnbom

\section{Title Page}

Abstract

Introduction

Conclusions

Tables

References

Figures

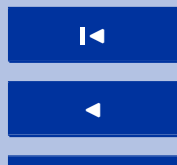

$\Delta$

Back

Close

Full Screen / Esc

Printer-friendly Version

Interactive Discussion

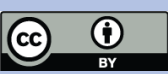


Gregory et al. (2004) plotted the changes in the TOA net downward radiative flux $N$ vs. the surface air temperature changes. The relaxation process in the model experiments resulted in straight lines, the slopes of which correspond to the feedback parameter $\alpha$, the intercepts on the $y$-axis give values of the radiative forcing and the 5 intercepts on the $\mathrm{x}$-axis are measures of the climate sensitivity in case of a $2 \times \mathrm{CO}_{2}$ model experiment.

Such plots were done for total net radiative flux, for long wave (LW) and for short wave (SW) flux.

Spencer and Braswell (2010) used the same conceptual framework and model equa10 tion for the net radiative flux for evaluating radiative flux observations with satellites. They reasoned that if satellite data of net radiative flux anomalies are plotted vs. temperature anomalies and the points are connected in time sequence to obtain a phase plane plot, segments of straight lines should appear in periods when the radiative forcing has a constant value. The slope of such segments would be equal to the feedback 15 parameter $\alpha$. If segments with the same slope would appear several times in the phase plane plot at difference to more randomly occurring slopes of other line segments this would be a strong indication that this slope corresponds to the feedback parameter value.

Spencer and Braswell (2010) used one month averaging and three month averag20 ing for CERES data. For data from The Earth Radiation Budget Experiment (ERBE) they used 216 days averages. They found indications of the expected segments of straight lines (also called striations) when using phase plane plots of the net radiative flux anomalies vs. middle troposphere temperature anomalies both using ERBE and CERES data. They selected the middle troposphere temperature because it is more correlated to the TOA radiative flux than the surface air temperature.

For the application of the method by Spencer and Braswell (2010) it is essential to use anomalies of the net radiative flux and the temperature in order to eliminate the seasonal variations. This is because the time periods are too short in order to plot only whole years as in the case of Gregory et al. (2004).
ESDD

$4,25-47,2013$

\section{Using radiative fluxes from CERES EBAF}

P. Björnbom

\section{Title Page}

Abstract Introduction

Conclusions

Tables References Figures

14

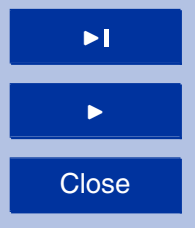

Back

Close

Printer-friendly Version

Interactive Discussion 
Spencer and Braswell (2010) also found interesting great loops in the phase plane diagrams, with large excursions of the temperature anomaly, especially in connection with the Mount Pinatubo cooling in ERBE data and with the 2008 La Niña cooling and subsequent warming in CERES data.

5 They further applied their phase plane method to the radiative flux data from AOGCMs where they studied phase planes not only with total net radiative flux but also with LW and SW fluxes. In those cases they used surface air temperature anomalies and 11 months low pass filtered averages. They studied periods of $50 \mathrm{yr}$ of length.

Indications of striations were found in the LW phase planes of four of the AOGCMs 10 and their slopes coincided with the feedback parameter values determined by Forster and Taylor (2006). However, in the phase plane diagrams for total net radiative flux or SW flux none of the AOGCMs produced significant striations. The result with LW phase planes is a support for the method since the AOGCMs confirm that if many striations appear with a common slope, this slope equals the value of the feedback parameter.

The present study is based on the idea of using phase plane plots according to Spencer and Braswell (2010). The main innovation in this study is the usage of phase plane plots where the radiative flux with a time lag is plotted vs surface temperature.

\section{Data and methods}

The TOA radiative flux data used was retrieved from the CERES EBAF product avail20 the calculation of anomalies are given in the supplementary material. Loeb et al. (2009) give a background of and discuss the design of the CERES EBAF product. The surface air temperature anomalies used are from HadCRUT3 (Brohan et al., 2006).

The monthly anomalies for the net radiative fluxes from CERES EBAF were calcu25 lated as deviations from the monthly averages for the period 2001-2011. Both the net radiative flux anomalies and the surface air temperature anomalies were smoothed by calculating running centered 13 months averages. The choice of 13 months for

\section{ESDD}

$4,25-47,2013$

\section{Using radiative fluxes from CERES EBAF}

P. Björnbom

\section{Title Page}

Abstract Introduction

Conclusions

Tables References Figures

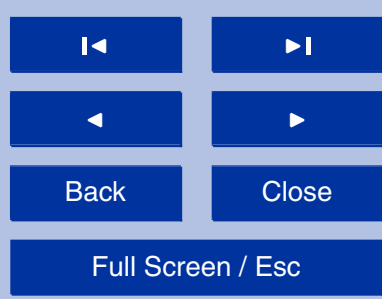

Printer-friendly Version

Interactive Discussion

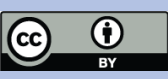


smoothing is suitable for comparing the results with those of Gregory et al. (2004) that are plotted annually.

\section{Results}

The net radiative flux anomalies calculated from CERES EBAF data are compared with 5 surface air temperature anomalies according to HadCRUT3. At first the two data series are plotted as a function of time and compared. After that various plots are discussed based on the phase plane method proposed by Spencer and Braswell (2010).

\subsection{Comparison of the time series}

In Fig. 1 the two time series of net radiative flux anomalies and the surface air temperature anomalies are plotted. Since the net radiative flux is defined as positive downwards and the upward radiative flux increases as a result of feedback from a temperature increase the negative radiative flux, $-N$, has been plotted for convenience. Note that the scale factor between the two $y$-axes is $6 \mathrm{Wm}^{-2} \mathrm{~K}^{-1}$.

Obviously a lead-lag relation can be seen in Fig. 1 between the surface temperature anomaly and the net radiative flux anomaly during the five year period of mid-2006 to mid-2011. This is especially obvious from how the turns in the temperature curve from increasing to decreasing and vice versa is followed by turns in the radiative flux curve but with a lag.

The part of the temperature curve of interest here starts with its turn from decreasing to increasing in the middle of 2006. At about the same time the outgoing net radiative flux anomaly also turns from decreasing to increasing. When the temperature anomaly after this turn increases the outgoing net radiative flux increases in the proportion of around $6 \mathrm{Wm}^{-2} \mathrm{~K}^{-1}$ with a time lag of around seven months.

After the temperature anomaly turns to decreasing at the beginning of 2007 the
ESDD

$4,25-47,2013$

\section{Using radiative fluxes from CERES EBAF}

P. Björnbom

\section{Title Page}

Abstract Introduction

Conclusions

Tables References

\section{Figures}

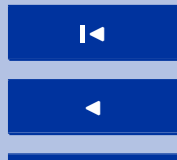

Back

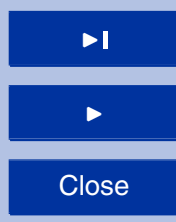

Full Screen / Esc

Printer-friendly Version

Interactive Discussion

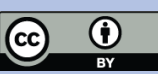


months. The net radiative flux anomaly continues to change in the proportion of around $6 \mathrm{Wm}^{-2} \mathrm{~K}^{-1}$ to the temperature anomaly.

The next time the temperature anomaly turns, then from decreasing to increasing, is at the beginning of 2008. Again the outgoing net radiative flux turns from decreas5 ing to increasing with a time lag, now possibly a little longer than seven months. The proportion between the change of the outgoing net radiative flux anomaly and the temperature anomaly change is still around $6 \mathrm{Wm}^{-2} \mathrm{~K}^{-1}$. Finally the temperature turns in the beginning of 2010 and again the net radiative flux turns, now a little earlier than with a seven months lag.

10 This time period was dominated by a series of alternating La Niña och an El Niño (NOAA, 2012). During such ENSO oscillations a large amount of heat is oscillating between the deep ocean and the mixed layer (Trenberth et al., 2010). Assuming that external radiative forcing may be neglected compared to the non-radiative forcing by the deep sea on the mixed layer during this period, the changes in net radiative flux anomaly should be dominated by the feedback from the temperature change.

Obviously the change in the net radiative flux anomaly is proportional to the change in the temperature anomaly with a lag. The proportionality factor is about $6 \mathrm{Wm}^{-2} \mathrm{~K}^{-1}$.

During the first period of the diagram there are also some lead-lag relations between the surface temperature anomaly and the net radiative flux anomaly. This is further discussed in the following.

\subsection{Phase plane plots}

In Fig. 2a the phase plane plot according to the method by Spencer and Braswell (2010) is given. Again the negative radiative flux, $-N$, has been plotted in order to follow the same sign convention as used by Spencer and Braswell (2010).

For comparison a red line with the slope $6 \mathrm{Wm}^{-2} \mathrm{~K}^{-1}$ has been inserted. In this diagram there are only a few short clear linear striations to be found with a slope close to $6 \mathrm{Wm}^{-2} \mathrm{~K}^{-1}$. Spencer and Braswell (2010) drew attention to the great loop seen in
ESDD

$4,25-47,2013$

\section{Using radiative fluxes from CERES EBAF}

P. Björnbom

\section{Title Page}

Abstract Introduction

Conclusions References

Tables Figures
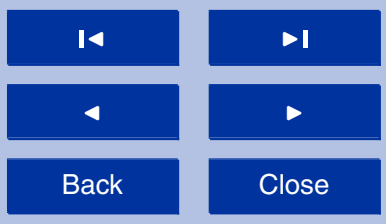

Back

Close

\section{Full Screen / Esc}

Printer-friendly Version

Interactive Discussion

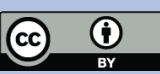


this diagram for the time period around the end of the decade with a La Niña and an El Niño but they did not further explore it.

However, two sine functions $x=a \sin (\omega t)$ and $y=b \sin (\omega t+\phi)$ with the same angular frequency but different phase give an elliptic loop in a phase plane plot. When the 5 phase shift $\phi \rightarrow 0$ this elliptic loop will approach a straight line $y-y_{0}=\frac{b}{a}\left(x-x_{0}\right)$.

We have already seen from Fig. 1 that the surface air temperature anomaly and the net radiative flux anomaly oscillate nearly as phase shifted sine functions during the five year period of mid-2006 to mid-2011. Hence a logical next step is to draw a phase plane plot with a lag based on the phase shift seen in Fig. 1. Figure $2 b$ shows a phase 10 plane plot where the net radiative flux anomaly lags the surface temperature anomaly with seven months. Again a red line with the slope $6 \mathrm{Wm}^{-2} \mathrm{~K}^{-1}$ has been inserted.

This plot is remarkable. During two time periods the curve closely approaches straight lines with a slope around $6 \mathrm{Wm}^{-2} \mathrm{~K}^{-1}$. The second five year long one of those two periods is clearly dominated by ENSO oscillations.

\subsection{Phase plane plots for mid-2006 to mid-2011}

According the hypothesis that the time period mid-2006 to mid-2011 was dominated by ENSO the external radiative forcing should have a minor importance. The changes in the surface temperature anomaly should be dominated by the non-radiative forcing by the deep ocean on the mixed layer. If we add the hypothesis that the feedback of the 20 net radiative flux anomaly from the changes in the surface temperature anomaly has a lag we should get the same lagged linear correlation albeit the dots are connected or not.

This is illustrated in Fig. 3a showing the phase plane plot for the five year time period mid-2006 to mid-2011. As before the time lag of the net radiative flux anomaly compared to the temperature anomaly is 7 months.

The red line is the least square regression line giving a slope of $5.3 \pm 0.6 \mathrm{Wm}^{-2} \mathrm{~K}^{-1}$. The error limits are given as twice the standard error. The $R^{2}$ value is 0.85 . Hence this combination of the methods used by Spencer and Braswell (2010) and by Trenberth et
ESDD

4, 25-47, 2013

\section{Using radiative fluxes from CERES EBAF}

P. Björnbom

\section{Title Page}

\section{Full Screen / Esc}

Printer-friendly Version

Interactive Discussion

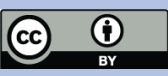


al. (2010) together with the assumption of a time lag for the feedback supports a high value of the climate feedback parameter.

However, that analysis does not account for the expected trend in external forcing. From NASA GISS forcings (2012) the trend in greenhouse gas forcing 2005-2010 was 5 estimated to approximately $0.04 \mathrm{~W} \mathrm{~m}^{-2} \mathrm{a}^{-1}$ and the trend in the net forcing was around $0.05 \mathrm{Wm}^{-2} \mathrm{a}^{-1}$.

Hence we should expect a corresponding small linear trend in the net radiative flux anomaly. To explore the possibility of such a linear lasting trend the net radiative flux anomaly data was also regressed to the following linear model:

$10-N(t)=F+\alpha \Delta T\left(t-t_{\text {lag }}\right)+b t$

In this case the slope $\alpha=5.5 \pm 0.6 \mathrm{Wm}^{-2} \mathrm{~K}^{-1}$ while $b=-0.025 \pm 0.030 \mathrm{Wm}^{-2} \mathrm{a}^{-1}$. The $R^{2}$ value is 0.86 . This result does not exclude a possible linear trend with a value around the forcing trends according to NASA GISS but due to the wide error limits no conclusion is possible. There may also be a trend in the CERES instrument of a few 15 multiples of $0.01 \mathrm{Wm}^{-2} \mathrm{a}^{-1}$ (Loeb et al., 2009).

In Fig. $3 b$ the same phase plane plot is seen together with the plot, the red see-saw line, of the calculated values according to the model Eq. (4).

\section{Discussion}

The time lag in the feedback of the net radiative flux to changes in the surface air 20 we have plotted $-N(t)$ vs. $\Delta T\left(t-t_{\mathrm{lag}}\right)$. However, according to Gregory et al. (2004) the feedback term in Eq. (1) is found to be proportional to the temperature change in climate models. Assuming that the time lag has not given much distortion of the results from climate model simulation results the following modified equation with at time lag

ESDD

$4,25-47,2013$

\section{Using radiative fluxes from CERES EBAF}

P. Björnbom

\section{Title Page}

Abstract Introduction

Conclusions

Tables References

\section{Figures}

1

DI

4

Back

Close

Full Screen / Esc

Printer-friendly Version

Interactive Discussion 
of $t_{\text {lag }}$ is proposed:

$N(t)=F-\alpha \Delta T\left(t-t_{\text {lag }}\right)$.

ESDD

\subsection{The hypothesis of a lag in the feedback}

How compatible is the hypothesis of a lag between the temperature anomaly change 5 and the feedback in the net radiative flux anomaly with the theory of Gregory et al. (2004)? Would the time lag not result in a distortion of the straight lines that are seen in the $2 \times \mathrm{CO}_{2}$ and $4 \times \mathrm{CO}_{2}$ experiments from the climate models used by Gregory et al. (2004)?

This question may be elucidated by comparing the phase plane plot from a $4 \times \mathrm{CO}_{2}$ 10 experiment with and without a time lag in the net radiative flux feedback. We will assume that the temperature response after quadrupling of the carbon dioxide mixing ratio follows the simple Energy Balance Model (EBM) as described by Andrews (2010, p.198).

The solution of the EBM to an instantaneous step change in the carbon dioxide 15 mixing ratio, resulting in a constant forcing of $F_{1} \mathrm{Wm}^{-2}$, is:

$\Delta T=\frac{F_{1}}{\alpha}(1-\exp (-t / \tau))$

This is not a rigorous solution of the temperature response in case of a feedback with a time lag, However, for the purpose of this analysis we only need the approximate form of the curve for the temperature response.

20 Assuming that the feedback in the net radiative flux occurs with a time lag of $t_{\text {lag }}$ the net radiative flux is described by Eq. (5) giving:

$N(t)=F_{1}-\alpha \Delta T\left(t-t_{\text {lag }}\right)=F_{1} \exp \left(-\left(t-t_{\text {lag }}\right) / \tau\right)$

In Fig. 4a those two equations have been plotted as a function of time with $t_{\text {lag }}=7$ months and with the parameter values in line with the $4 \times \mathrm{CO}_{2}$ experiments in Gregory

\section{Using radiative fluxes from CERES EBAF}

P. Björnbom

Title Page

Abstract Introduction

Conclusions

Tables References Figures
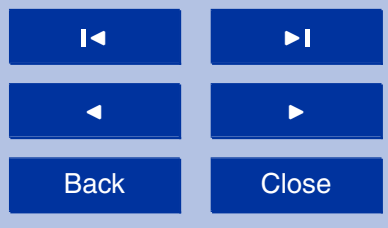

Full Screen / Esc

Printer-friendly Version

Interactive Discussion 
et al. (2004):

$$
\begin{aligned}
\alpha & =1.2 \mathrm{Wm}^{-2} \mathrm{~K}^{-1} \\
F_{1} & =7.4 \mathrm{Wm}^{-2} \\
\tau & =10 \mathrm{yr}
\end{aligned}
$$

5 Note that $-N$ for convenience has been plotted in Fig. $4 \mathrm{a}$ and that the scale factor between the two y-axes equals $\alpha$.

In Fig. 4 the phase plane plots with (red) and without (blue) the seven months lag time are shown. Here $N$ has been plotted in order to follow same sign convention for the net radiative flux as in Gregory et al. (2004). Note that in the case without time lag 10 the straight line merely is a consequence of the assumption in the EBM that Eq. (3) is valid. Obviously a time lag of seven months has only a minor effect on the slope and the intercept of the straight line according to the method by Gregory et al. (2004). The phase plane plots in Fig. $4 \mathrm{~b}$ are very similar to the plots in Figs. 1 and 2 in Gregory et al. (2004).

15 The small impact of the time lag according to Fig. $4 \mathrm{~b}$ may be explained by the form of the temperature curve. The curve is monotonically increasing with slowly changing slope compared to the time scale of the time lag. With the rapidly changing see-saw type of curve according Fig. 1 we have another case where the time lag has a considerable impact and cannot be neglected in the analysis.

20 Similar lead-lag relations have previously been observed according to the literature. Lindzen and Choi (2011) in their attempt to estimate the climate feedback parameter found that it is important to consider a lag between surface temperature changes and feedback in the TOA radiative flux. Their study concerned the tropics and they made a linear regression using changes in the anomalies of TOA radiative fluxes against changes in the sea surface temperature anomalies (SST). Best correlations were obtained with a few months of lag between the SST and the radiative fluxes. Further observations of similar lead-lag relations have been reported (Spencer and Braswell, 2011; Trenberth et al., 2011; Dessler, 2011). Such lead-lag relations are also found

ESDD

$4,25-47,2013$

\section{Using radiative fluxes from CERES EBAF}

P. Björnbom

\section{Title Page}

Abstract Introduction

Conclusions

Tables References Figures
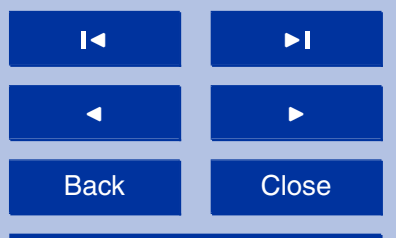

Full Screen / Esc

Printer-friendly Version

Interactive Discussion 
in the results from advanced climate models (Lindzen and Choi, 2011; Spencer and Braswell, 2011; Trenberth et al., 2011; Dessler, 2011).

Considering water vapor, clouds, precipitation, global circulation etc. as an integrated system, as described by Stephens (2005), which gives feedback in the TOA radiative 5 flux from global temperature changes, it seems reasonable to assume a lead-lag relation. Especially if the global temperature change is forced in connection with the ENSO there should be a considerable lag time before the temperature change has resulted in feedback from the whole planet.

\subsection{The length of the time period}

10 How reasonable is the length of the time period, mid-2006 to mid-2011, for our estimate of the climate feedback parameter? From Figs. 1 and 2 in Gregory et al. (2004) we can see that according to a $4 \times \mathrm{CO}_{2}$ experiment a time period of five years may give a fairly well defined straight line in the phase plane plot with a slope equal to the climate feedback parameter. We may also note that the variation in the net radiative flux during 15 this five year period according to Gregory et al. (2004) is about $3 \mathrm{Wm}^{-2}$ for a $4 \times \mathrm{CO}_{2}$ experiment and half of that for a $2 \times \mathrm{CO}_{2}$ experiment. This is in the same range as the variations we see in Fig. 3 in this work.

Thus the resuts from the climate models support that a five year period used for estimating the climate feedback parameter may well give a reasonable result. Further 20 support for getting a reasonable value is that also the variations in net radiative flux are in a similar range as in the climate model experiments,

\subsection{Comparing methods}

What are the similarities and differences between the method by Gregory et al. (2004) and the method studied here? Let us use Eq. (5), $N(t)=F-\alpha \Delta T\left(t-t_{\text {lag }}\right)$, as a basis 25 for the comparison.
ESDD

$4,25-47,2013$

\section{Using radiative fluxes from CERES EBAF}

P. Björnbom

\section{Title Page}

Abstract Introduction

Conclusions

Tables References Figures

14

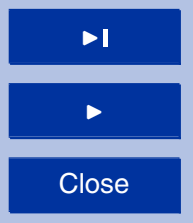

Back

Close

Full Screen / Esc

Printer-friendly Version

Interactive Discussion 
In Gregory et al. (2004) $F$, after the initial large step perturbation, varies randomly around an average due to the natural variations that the climate model expresses. Hence the points in the phase plane plot approach a straight line with the slope of $-\alpha$ when $N(t)$ is plotted vs $\Delta T\left(t-t_{\text {lag }}\right)$. This method may be used for evaluating climate 5 model experiments but is not useful for the real climate system.

The method studied in this work may be applied to the real climate system. In this case $F$ varies much less than $\alpha \Delta T\left(t-t_{\text {lag }}\right)$ because $\Delta T$ is assumed to get large changes due to non-radiative forcing from the deep sea on the mixed layer during time periods dominated by ENSO episodes. Hence the points in the phase plane plot ap10 proach a straight line with the slope $\alpha$ when $-N(t)$ is plotted vs $\Delta T\left(t-t_{\text {lag }}\right)$ (if we make the phase plane plot according to the sign convention used by Spencer and Braswell, 2010).

Due to the shape of the temperature response the time lag may be neglected in the first method but not in the second.

15 By using a variation of the EBM Spencer and Braswell (2010) have demonstrated how linear striations with a slope equal to the climate feedback parameter may appear in the phase-plane when non-radiative forcing is acting on the climate system in time periods with little variations in the radiative forcing. Here we have found such a case where the dominating forcing of the climate system is non-radiative in connection with ENSO during a five year period.

The reason that a longer ENSO-driven period with a dominating non-radiative forcing has not been considered in previous work is that the possibility of a time lag in the feedback process was not explored. Thus Spencer and Braswell (2010) found a great loop in the phase-plane plot during the La Niña 2008. According to Eq. (3) such a loop should mean large variations in the radiative forcing $F$. However, our results suggest that Eq. (3) is too approximative in our case and it must be modified to account for the time lag in the feedback process resulting into Eq. (5).
ESDD

$4,25-47,2013$

\section{Using radiative fluxes from CERES EBAF}

P. Björnbom

\section{Title Page}

Abstract Introduction

Conclusions

Tables References Figures

14

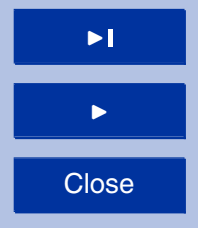

Back

Close

Full Screen / Esc

Printer-friendly Version

Interactive Discussion

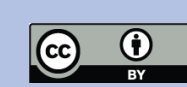




\subsection{Comparing time intervals}

Two time intervals by our hypothesis are assumed to be dominated by ENSO episodes while one is not. There was a strong La Niña JJA98-FMA01 (NOAA, 2012). The first time interval showing a straight line in Fig. 2b, May 2001-January 2002 may be con5 nected to the final global recovery from this ENSO episode although this is not very clear.

Then we have the time period January 2002-May 2006. See Fig. 1. Although there was a strong EI Niño AMJ02-JFM03 (NOAA, 2012) this seems not to have given much non-radiative forcing compared to radiative forcing. There is furthermore a drop in the temperature curve in the second half of 2002 followed by a drop in the radiative flux curve with a lag but this cannot be explained by any ENSO episode. The whole period seems mostly to be characterized by variations of similar magnitude in both terms in the right hand side of Eq. (5).

The final time interval May 2006-June 2011 may be explained by a series of alter15 nating La Niña and El Niño beginning with a La Niña at OND05 (NOAA, 2012). This alternating ENSO sequence according to our hypothesis causes the temperature curve to oscillate due to the effect of non-radiative forcing. Consequently the second term in the right hand side in Eq. (5) dominates during this time interval making it suitable for estimating $\alpha$.

\subsection{The relevance of the climate feedback parameter value}

Compared to a step forcing change experiment in our case the net radiative flux and the temperature are varying at a much higher rate, including changes between increasing and decreasing values. Since according to our hypothesis the temperature change is the cause and the net radiative flux change is the effect it is possible that there is some sort of inertia effect in the radiative flux changes. In that case those changes would become smaller than in a step change experiment giving a smaller value of the climate feedback parameter than otherwise.

\section{ESDD}

$4,25-47,2013$

\section{Using radiative fluxes from CERES EBAF}

P. Björnbom

\section{Title Page}

Abstract Introduction

Conclusions

Tables References Figures

14

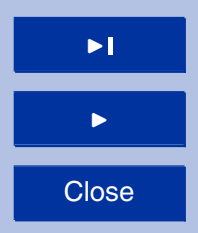

Back

Close

Full Screen / Esc

Printer-friendly Version

Interactive Discussion

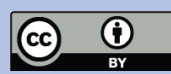


On the other hand in a step change experiment progressing over multidecadal periods the climate model may account for such feedbacks as changes in the cryosphere. Such feedbacks are unlikely to be seen for a period of only five years as studied in this work. This effect would possibly give a too large value of the climate feedback 5 parameter in our case.

Another issue to be considered in future work should be that the large value of the climate feedback parameter according to this work disagrees with much of the literature on climate sensitivity (Knutti and Hegerl, 2008; Randall et al., 2007; Huber et al., 2011). However, the value found here agrees with the report by Spencer and Braswell 10 (2010) that whenever linear striations were observed in their phase plane plots the slope was around $6 \mathrm{Wm}^{-2} \mathrm{~K}^{-1}$. Spencer and Braswell (2010) used middle tropospheric temperature anomalies and although they did not consider any time lag they may have observed some feedback processes with negligible time lag considering that the tropospheric temperature is better correlated to the radiative flux than the surface air

15 temperature. The value found in this study also agrees with Lindzen and Choi (2011) who also considered the effects of lead-lag relations.

\section{Conclusions}

The analysis of the time series in Fig. 1 suggest a clear lead-lag relation between the variations in the surface air temperature anomaly and the TOA net radiative flux 20 anomaly during two parts of the observed time period September 2000-May 2011. During those two time periods, about eight months at the beginning and five years at the end, the net radiative flux anomaly lags the surface air temperature anomaly with around seven months.

This observation was confirmed by using a phase plane plot of the net radiative flux 25

\section{ESDD}

$4,25-47,2013$

\section{Using radiative fluxes from CERES EBAF}

P. Björnbom

\section{Title Page}

Abstract Introduction

Conclusions

Tables References

\section{Figures}

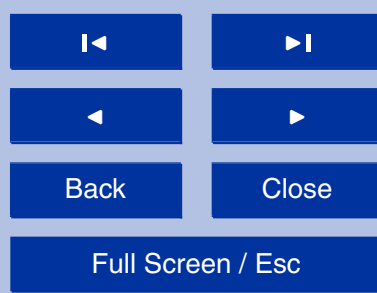

Printer-friendly Version

Interactive Discussion two time periods the phase plane curve approaches straight lines with a slope around $6 \mathrm{Wm}^{-2} \mathrm{~K}^{-1}$. 
Those results, but more clearly in case of the second five year period, support the hypothesis that such lead-lag relations, exhibiting straight lines in the phase plane plots, occur when non-radiative forcing is dominating the changes in the temperature due to ENSO episodes, while the variations in radiative forcing are comparatively negligible. 5 The data could be interpreted using Eq. (5) describing the relation between the lagged net radiative flux anomaly and the surface air temperature anomaly.

Using Eq. (5) as a linear regression model for the five year period mid-2006 to mid2011 gave, as illustrated in Fig. 3, a value of the climate feedback parameter of $\alpha=$ $5.5 \pm 0.6 \mathrm{Wm}^{-2} \mathrm{~K}^{-1}$.

10 Supplementary material related to this article is available online at: http://www.earth-syst-dynam-discuss.net/4/25/2013/esdd-4-25-2013-supplement. pdf.

Acknowledgements. The author thanks the writers and denizens of the blog Stockholmsinitiativet for valuable criticism and for encouragement to submit this study to a scientific journal.

\section{References}

Andrews, D. G.: An Introduction to Atmospheric Physics, Cambridge University Press, UK, 2010. 35

Brohan, P., Kennedy, J. J., Harris, I., Tett, S. F. B., and Jones, P. D.: Uncertainty estimates in regional and global observed temperature changes: A new data set from 1850, J. Geophys.

20 Res., 111, D12106, doi:10.1029/2005JD006548, 2006. 30

Dessler, A. E.: A determination of the cloud feedback from climate variations over the past decade, Science, 330, 1523-1527, doi:10.1126/science.1192546, 2010. 27

Dessler, A. E.: Cloud variations and the Earths energy budget, Geophys. Res. Lett., 38, L19701, doi:10.1029/2011GL049236, 2011. 27, 36, 37

25 Forster, P. M. and Taylor K. E.: Climate forcings and climate sensitivities diagnosed from coupled climate model integrations, J. Climate, 19, 6181-6194, 2006. 30

\section{ESDD}

$4,25-47,2013$

\section{Using radiative fluxes from CERES EBAF}

P. Björnbom
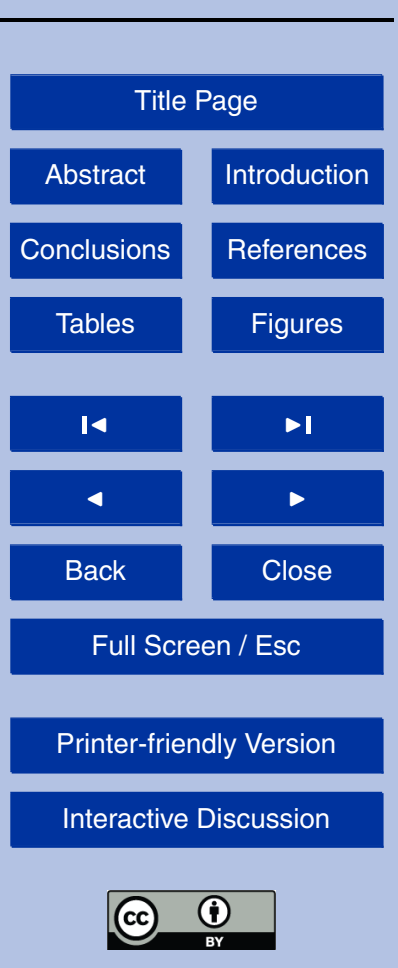
Gregory, J. M., Ingram, W. J., Palmer, M. A., Jones, G. S., Stott, P. A., Thorpe, R. B., Lowe, J. A., Johns, T. C., and Williams, K. D.: A new method for diagnosing radiative forcing and climate sensitivity, Geophys. Res. Lett. 31, L03205, doi:10.1029/2003GL018747, 2004. 27, $28,29,31,34,35,36,37,38$

5 Huber, M., Mahlstein I., Wild M., Fasullo J., and Knutti R.: Constraints on climate sensitivity from radiation patterns in climate models, J. Climate, 24, 1034-1052, doi:10.1175/2010JCLI3403.1, 2011. 27, 40

Knutti, R. and Hegerl, G. C.: The equilibrium sensitivity of the Earth's temperature to radiation change, Nat. Geosci., 1, 735-743, doi:10.1038/ngeo337, 2008. 27, 40

10 Lindzen, R. S. and Choi, Y.-S.: On the observational determination of climate sensitivity and its implications, Asia-Pacific, J. Atmos. Sci., 47, 377-390, doi:10.1007/s13143-011-0023-x, 2011. 36, 37, 40

Loeb, N. G., Wielicki, B. A., Doelling, D. R. , Smith, G. L., Keyes, D. F., Kato, S., Manlo-Smith, N., and Wong, T.: Toward Optimal Closure of the Earth's TOA Radiation Budget, J. Climate,

Loeb, N. G., Kato, S., Su,W.,Wong, T., Rose, F. G., Doelling, D. R., Norris, J. R., and Huang, X.: Advances in Understanding Top-of-Atmosphere Radiation Variability from Satellite Observations, Surv. Geophys., 33, 359-385, doi:10.1007/s10712-012-9175-1, 2012. 27

Masters, T.: On the determination of the global cloud feedback from satellite measurements,

20 Earth Syst. Dynam., 3, 97-107, doi:10.5194/esd-3-97-2012, 2012. 26, 27

NASA. CERES EBAF Data Sets: http://ceres-tool.larc.nasa.gov/ord-tool/jsp/EBAFSelection. jsp, last access: 17 June, 2012. 30

NASA GISS Forcings: available at: http://data.giss.nasa.gov/modelforce/, last access: 25 November, 2012. 34

NOAA Historical El Nino/ La Nina episodes (1950-present): available at: http://www.cpc.ncep. noaa.gov/products/analysis_monitoring/ensostuff/ensoyears.shtml, last access: 14 December, 2012. 32, 39

Spencer, R. W. and Braswell, W. D.: On the diagnosis of radiative feedback in the presence of unknown radiative forcing. J. Geophys. Res., 115, D16109, doi:10.1029/2009JD013371, $30 \quad 2010.27,28,29,30,31,32,33,38,40$

Spencer, R. W. and Braswell W. D.: On the misdiagnosis of surface temperature feedbacks from variations in Earth's radiant energy balance, Remote Sens., 3, 1603-1613, doi:10.3390/rs3081603, 2011. 36, 37
ESDD

4, 25-47, 2013

\section{Using radiative fluxes from CERES EBAF}

P. Björnbom

\section{Title Page}

Abstract Introduction

Conclusions References

Tables Figures

14

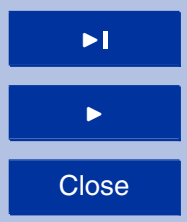

Back

Close

\section{Full Screen / Esc}

Printer-friendly Version

Interactive Discussion

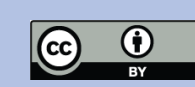


Stephens, G. L.: Cloud feedbacks in the climate system: A critical review, J. Climate, 18, 237273, 2005. 37

Randall, D. A., Wood, R. A., Bony, S., Colman, R., Fichefet, T., Fyfe, J., Kattsov, V., Pitman, A., Shukla, J., Srinivasan, J., Stouffer, R. J., Sumi, A., and Taylor, K. E.: Climate Models and Their Evaluation, in: Climate Change 2007: The Physical Science Basis. Contribution of Working Group I to the Fourth Assessment Report of the Intergovernmental Panel on Climate Change, edited by: Solomon, S., Qin, D., Manning, M., Chen, Z., Marquis, M., Averyt, K. B., Tignor, M., and Miller, H. L., Cambridge University Press, Cambridge, UK and New York, NY, USA, 2007. 27, 40

10 Trenberth, K. E., Fasullo, J. T., O'Dell, C., and Wong, T.: Relationships between tropical sea surface temperature and top-of-atmosphere radiation, Geophys. Res. Lett., 37, L03702, doi:10.1029/2009GL042314, 2010. 26, 27, 32, 33

Trenberth, K. E., Fasullo, J. T., and Abraham, J. P.: Issues in Establishing Climate Sensitivity in Recent Studies, Remote Sens, 3, 2051-2056, 2011. 26, 27, 36, 37

\section{ESDD}

$4,25-47,2013$

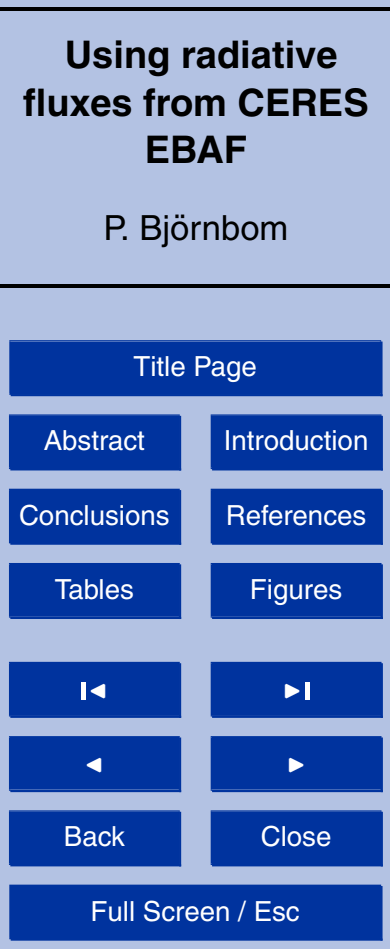

Printer-friendly Version

Interactive Discussion 


\section{ESDD}

$4,25-47,2013$

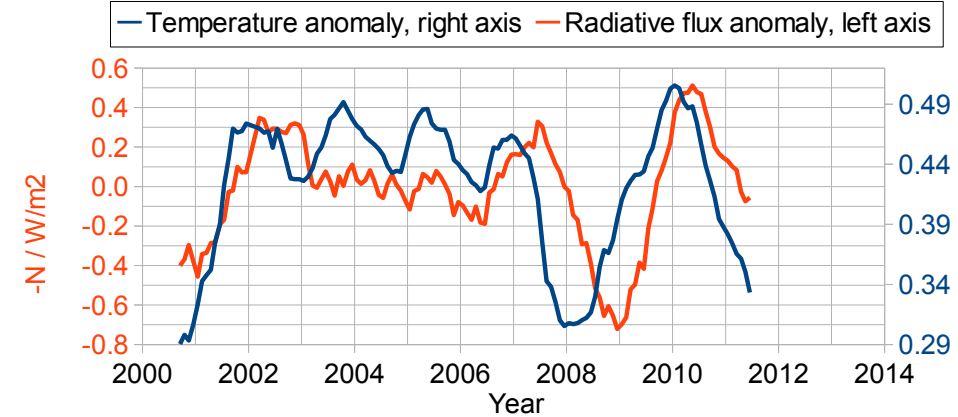

Fig. 1. Thirteen months running averages of net radiative flux anomalies and surface air temperature anomalies plotted as functions of time.

\section{Using radiative fluxes from CERES EBAF \\ P. Björnbom \\ Title Page \\ Abstract \\ Introduction \\ Conclusions \\ References \\ Tables \\ Figures \\ 14 \\ 4 \\ Back

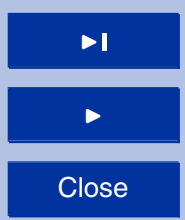 \\ Full Screen / Esc \\ Printer-friendly Version \\ Interactive Discussion}

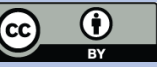




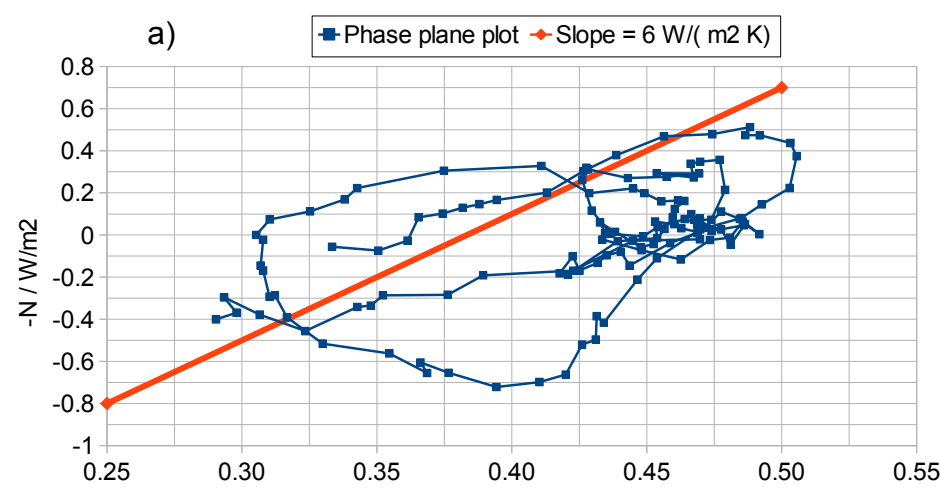

ESDD

$4,25-47,2013$

\section{Using radiative fluxes from CERES EBAF \\ P. Björnbom}

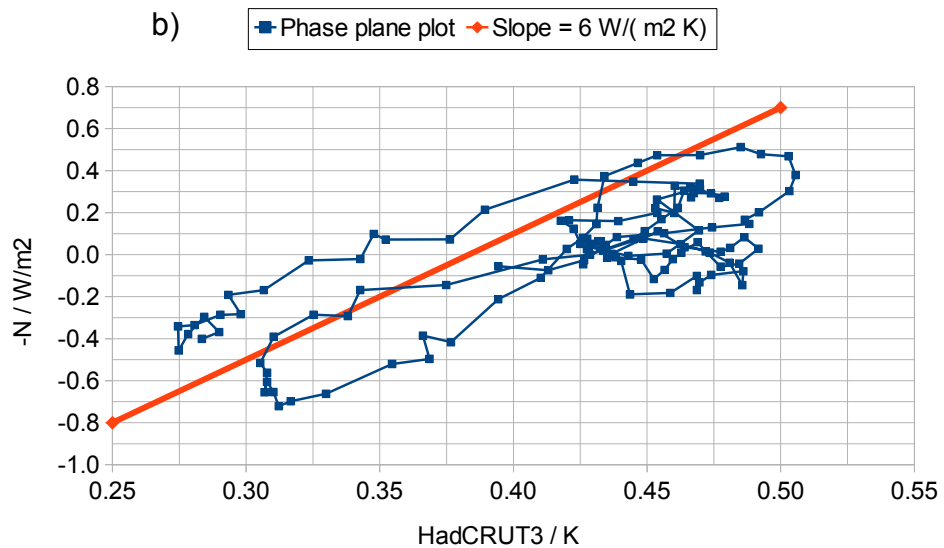

\begin{tabular}{|c|c|}
\hline Abstract & Introduction \\
\hline Conclusions & References \\
\hline Tables & Figures \\
\hline & \\
\hline I4 & $\bullet$ \\
\hline 4 & $\checkmark$ \\
\hline Back & Close \\
\hline Full Screen / Esc \\
\hline Printer-friendly Version \\
\hline Interactive Discussion
\end{tabular}

Fig. 2. Phase plane plots of the same data as in Fig. 1. Net radiative flux anomalies are plotted vs surface air temperature anomalies. In (a) there is no lag while in (b) the net radiative flux anomalies lag the temperature anomalies with seven months.

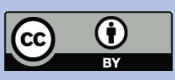




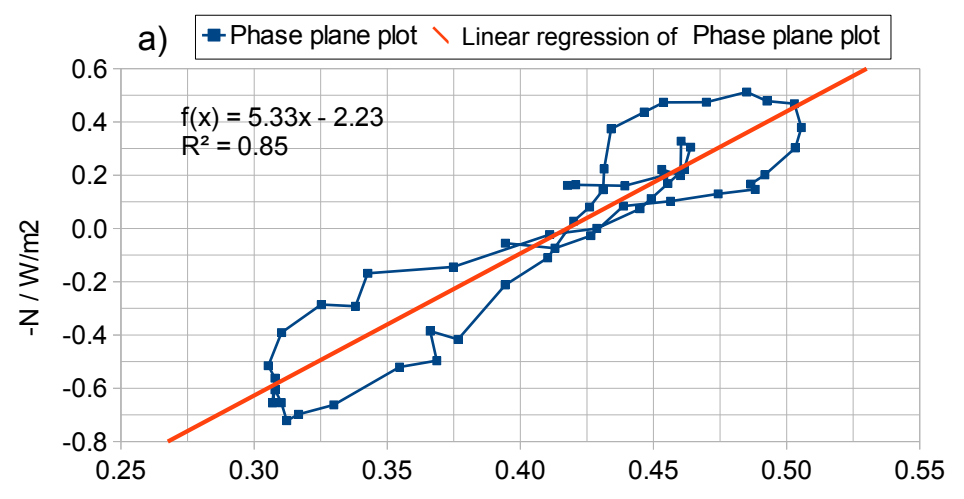

\section{ESDD}

$4,25-47,2013$

\section{Using radiative fluxes from CERES EBAF \\ P. Björnbom}

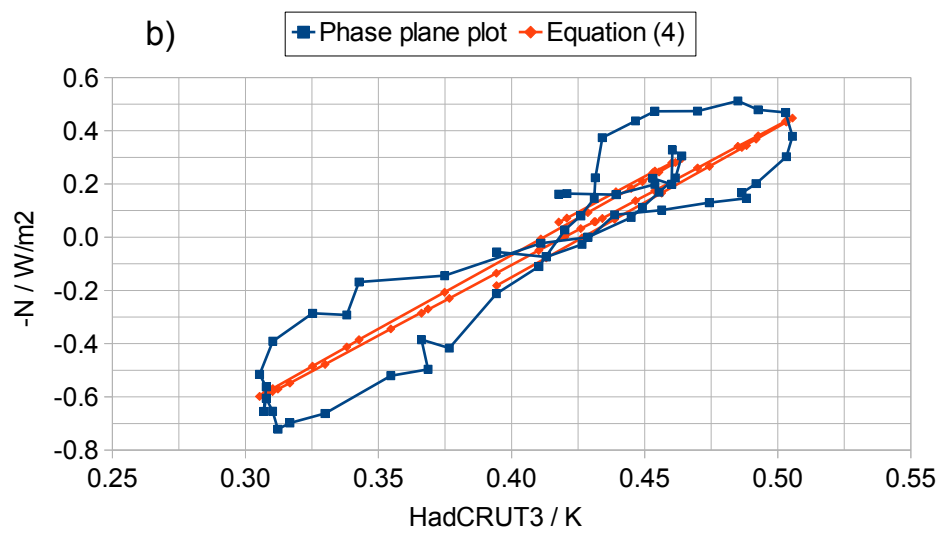

Fig. 3. Phase plane plots like in Fig. $2 b$ with seven months lag but for the time interval mid-2006 to mid-2011. In (a) wih constant forcing $F$ according to Eq. (5). In (b) a possible linear trend in the forcing has been considered according to Eq. (4).

Title Page

\section{Abstract}

Conclusions

Tables

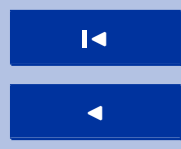

Back
Introduction

References

\section{Figures}

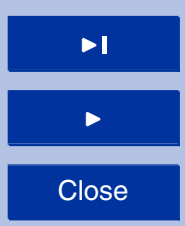

Full Screen / Esc

Printer-friendly Version

Interactive Discussion 


\section{ESDD}

a)

- Temperature change, right axis $\nleftarrow$ Radiative flux, left axis
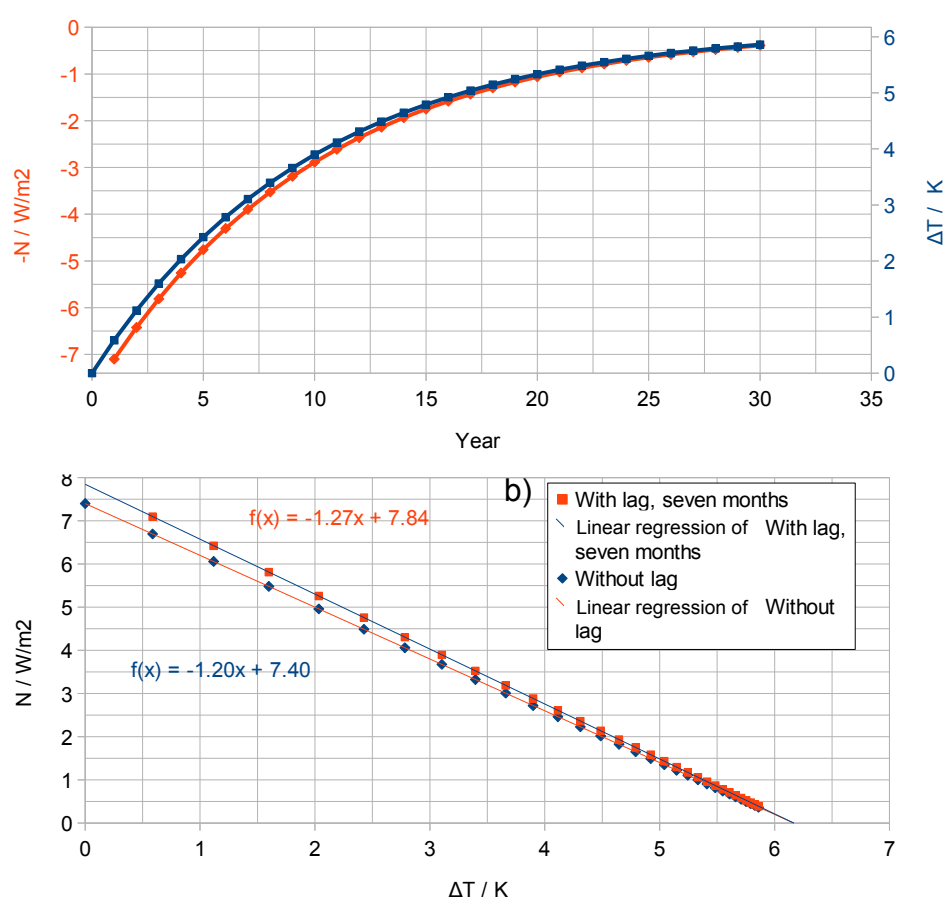

Fig. 4. (a) Net radiative flux change and temperature change plotted as a function of time for a $4 \times \mathrm{CO}_{2}$ experiment with a lag in the net radiative flux change as explained in the text. (b) Phase plane plots of a $4 \times \mathrm{CO}_{2}$ experiment with and without a lag in the net radiative flux change.
$4,25-47,2013$

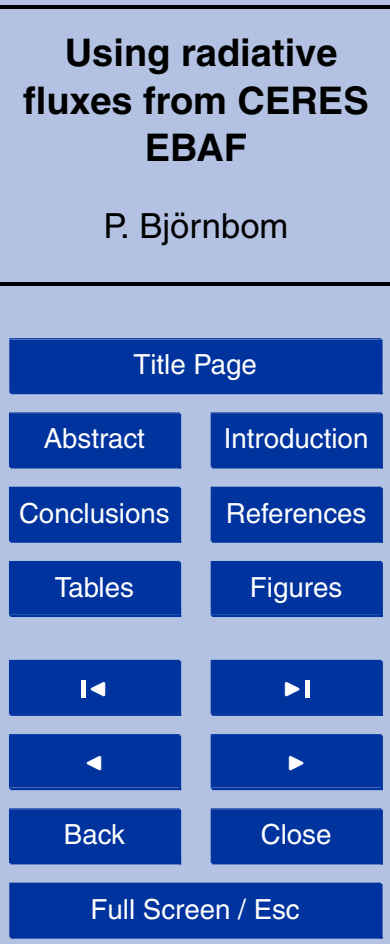

Printer-friendly Version

Interactive Discussion 